\title{
Cancer stem cell subpopulations in metastatic melanoma to the brain express components of the renin-angiotensin system
}

\author{
Agadha C. Wickremesekera ${ }^{1,2}$, Helen D. Brasch ${ }^{1}$, Valerie M. Lee ${ }^{1}$, Paul F. Davis $^{1}$, Andrew Parker ${ }^{2}$, Helge \\ Koeck ${ }^{2}$, Tinte Itinteang ${ }^{1 \#, ~ S w e e ~ T . ~ T a n ~}{ }^{1,3 \#}$ \\ ${ }^{1}$ Gillies Mclndoe Research Institute, Wellington 6242, New Zealand. \\ 2Department of Neurosurgery, Wellington Regional Hospital, Wellington 6021, New Zealand. \\ ${ }^{3}$ Wellington Regional Plastic, Maxillofacial \& Burns Unit, Hutt Hospital, Wellington, Lower Hutt 5010, New Zealand. \\ \#Equal senior authors.
}

Correspondence to: Dr. Swee T Tan, Gillies McIndoe Research Institute, PO Box 7184, Newtown, Wellington 6242, New Zealand. E-mail: swee.tan@gmri.org.nz

How to cite this article: Wickremesekera AC, Brasch HD, Lee VM, Davis PF, Parker A, Koeck H, Itinteang T, Tan ST. Cancer stem cell subpopulations in metastatic melanoma to the brain express components of the renin-angiotensin system. $J$ Cancer Metastasis Treat2019;5:62. http://dx.doi.org/10.20517/2394-4722.2019.009

Received: 29 Apr 2019 First Decision: 11 Jul 2019 Revised: 11 Jul 2019 Accepted: 6 Aug 2019 Published: 27 Aug 2019

Science Editor: Ira-Ida Skvortsova Copy Editor: Jia-Jia Meng Production Editor: Jing Yu

\begin{abstract}
Aim: There is increasing appreciation of the role of the renin-angiotensin system (RAS) in carcinogenesis with recent evidence showing expression of the RAS by cancer stem cells (CSCs) in different types of cancer. We have recently demonstrated the presence of three CSC subpopulations within metastatic melanoma (MM) to the brain: a Melan- $\mathrm{A}^{+}$subpopulation and a Melan- $\mathrm{A}^{-}$subpopulation within the tumor that express OCT4, SALL4, SOX2 and NANOG; and a pSTAT3 ${ }^{+}$subpopulation localized to the CD34+ endothelium of microvessels within the tumor. In this study we investigated the expression and localization of components of the RAS in relation to these CSCs in MM to the brain.
\end{abstract}

Methods: 3, 3-diaminobenzidine immunohistochemical (IHC) staining of components of the RAS: pro-renin receptor (PRR), angiotensin converting enzyme (ACE), angiotensin II receptor 1 (ATIIR1) and angiotensin II receptor 2 (ATIIR2) was performed on the same ten samples of MM to the brain included in our previous study. Immunofluorescence IHC staining of these components of the RAS was performed with embryonic stem cell markers OCT4 and NANOG, and endothelial marker CD34, on two of the samples of MM to the brain from the original cohort of ten patients. Western blotting $(n=5)$ and NanoString mRNA analysis $(n=4)$ were performed on samples of MM to the brain to confirm protein and mRNA expression of these components of the RAS, respectively.

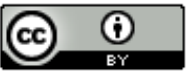

(C) The Author(s) 2019. Open Access This article is licensed under a Creative Commons Attribution 4.0 International License (https://creativecommons.org/licenses/by/4.0/), which permits unrestricted use, sharing, adaptation, distribution and reproduction in any medium or format, for any purpose, even commercially, as long as you give appropriate credit to the original author(s) and the source, provide a link to the Creative Commons license, and indicate if changes were made.

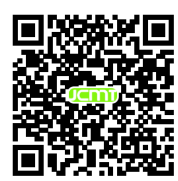


Results: DAB IHC staining showed the presence of PRR, ACE, ATIIR1 and ATIIR2 in all ten samples of MM to the brain. IF IHC staining showed that the CSC subpopulations in MM to the brain expressed PRR, ATIIR1 and ATIIR2; and a CSC subpopulation on the endothelium of the microvessels expressed ACE. Western blotting and NanoString mRNA analysis confirmed protein and mRNA expression of these components of the RAS, respectively.

Conclusion: CSCs in MM to the brain expressed components of the RAS. Targeting the CSCs using modulators of the RAS may be a novel therapeutic approach for treating this aggressive cancer.

Keywords: Malignant melanoma, metastatic, cancer stem cells, renin-angiotensin system, cancer, brain

\section{INTRODUCTION}

Metastatic melanoma (MM) to the brain occurs in 30\% of melanoma patients and accounts for $5 \%-8 \%$ of all brain tumors ${ }^{[1]}$. For many years, the median survival of MM to the brain is 6-9 months following mainstay treatments including surgical excision, stereotactic radiosurgery and external beam radiotherapy ${ }^{[2-5]}$. Investigations into MM to the brain have identified real time preferential hematogenous dissemination of tumor cells ${ }^{[6]}$, with survival of these cells within brain capillaries, migration to breach the blood brain barrier, angiogenesis and intraparenchymal proliferation ${ }^{[7]}$.

Although immunotherapies that enhance T-lymphocyte activity such as Ipilimumab, anti-cytotoxic T-lymphocyte associated antigen-4 and anti-programmed cell death-1 inhibitors can improve the median survival, some cause significant toxicities ${ }^{[8,9]}$. Up to 50\%-60\% of MM patients harbor the BRAF V600 somatic mutation ${ }^{[10]}$. Vemurafenib, a BRAF inhibitor, increases the median survival to 16 months ${ }^{[1]}$ but despite an initially good response, progression-free survival remains poor, at seven months ${ }^{[5]}$. Used together, kinase inhibitors, BRAF-targeted and MEK-targeted small molecule drugs relieve intracranial symptoms and induces remission but cessation due to toxicity causes rapid intracranial and/or extracranial disease progression ${ }^{[12]}$. The short period of remission after neuro-mimicry and individualized tumor targets ${ }^{[13]}$ has been attributed to the initiation, propagation and differentiation of cancer stem cells $(\mathrm{CSCs})^{[14]}$.

The CSC concept proposes that cancer is caused by CSCs that possess the ability for uncontrolled growth and propagation ${ }^{[15]}$. CSCs have been demonstrated in many types of cancer including breast carcinoma ${ }^{[16]}$, glioblastoma ${ }^{[17]}$ and oral cavity squamous cell carcinoma (OCSCC ${ }^{[18-20]}$. We have recently identified and characterized three CSC subpopulations within MM to the brain: a Melan- $\mathrm{A}^{+}$subpopulation and a Melan-A subpopulations that express embryonic stem cell (ESC) markers OCT4, SALL4, SOX2 and NANOG within the tumor, and a $\mathrm{PSTAT3}^{+}$subpopulation localized to the $\mathrm{CD} 34^{+}$endothelium of microvessels within the tumor ${ }^{[21]}$.

The RAS has been linked to carcinogenesis for some time ${ }^{[22]}$. In the classical RAS, angiotensinogen (ANG) is converted to angiotensin I (ATI) by renin. ATI is then converted to angiotensin II (ATII) by angiotensin converting enzyme (ACE). The RAS is implicated in central nervous system disorders such as Parkinson's disease and dementia with neuroprotective and neurotoxic features although its role in carcinogenesis is not discussed in a recent review ${ }^{[23]}$. GB cells in culture express ANG, pro-renin, ACE, ATII, angiotensin II receptor 1 (ATIIR1) and angiotensin II receptor 2 (ATIIR2); and renin inhibitors decrease DNA synthesis, induce apoptosis and reduce viable cell numbers ${ }^{[24]}$. Renin and its precursor pro-renin bind to pro-renin receptor (PRR) to activate the MAPK signaling cascades. PRR is associated with increased cell proliferation, decreased apoptosis and highly expressed in pancreatic ductal adenocarcinoma ${ }^{[25]}$. CSC subpopulations in $\mathrm{GB}^{[26]}$ and OCSCC of different subsites ${ }^{[27-29]}$ express components of RAS. 
We here hypothesized expression of the RAS by CSCs in MM to the brain and investigated the expression and localization of components of the RAS: PRR, ACE, ATIIR1 and ATIIR2, in relation to the putative CSC subpopulations we have recently identified ${ }^{[21]}$, using immunohistochemical (IHC) staining, Western blotting (WB) and NanoString mRNA analysis.

\section{METHODS}

\section{Tissue samples}

Samples of MM to the brain from ten patients were sourced from the Gillies McIndoe Research Institute Tissue Bank and used in this study that was approved by the Central Health and Disabilities Ethics Committee (Ref. 15CEN28) with written informed consent from all participants.

\section{Histology and IHC staining}

Hematoxylin and eosin (H\&E) staining was performed on $4 \mu \mathrm{m}$ thick formalin-fixed paraffin-embedded sections of MM to the brain from ten patients included in our previous study ${ }^{[2]}$, to confirm the presence of the tumor by an anatomical pathologist (HDB). 3,3-diaminobenzidine (DAB) IHC staining for CD34 (ready-to-use, cat\# PA0212, Leica), Melan-A (ready-to-use, cat\# PA0233, Leica), ACE (1:100; cat\# MCA2054, AbD Serotec, Kidlington, UK), PRR (1:2000; cat\# ab40790, Abcam), ATIIR1 (1:30; cat\# ab9391, Abcam), ATIIR2 (1:2000; cat\# NBP1-77368, Novus Biologicals, LLC, Littleton, CO, USA) as well as NANOG (1:100; cat\# ab80892, Abcam, Cambridge, UK), OCT4 (1:1000; cat\# ab109183, Abcam) and ERG (1:200; EPII, Cell Marque, Rocklin, CA, USA), diluted with Bond ${ }^{\mathrm{TM}}$ primary antibody diluent (cat\# AR9352, Leica), was performed as previously described ${ }^{[30]}$.

To localize the components of the RAS in relation to the putative Melan- $\mathrm{A}^{+}$and Melan- $\mathrm{A}^{-} \mathrm{OCT}_{4}{ }^{+} /$ $\mathrm{SALL}^{+} / \mathrm{SOX}_{2}{ }^{+} / \mathrm{NANOG}^{+} \mathrm{CSC}$ subpopulations within the tumor, and the $\mathrm{pSTAT}^{+}$subpopulation on the endothelium of microvessels within MM to the brain ${ }^{[21]}$, immunofluorescence (IF) IHC staining was performed on two representative samples of $M M$ to the brain from the original cohort of ten patients included for DAB IHC staining. Components of the RAS were co-stained with ESC markers OCT4 or NANOG as the surrogate markers for the Melan- $\mathrm{A}^{+}$and the Melan- $\mathrm{A}^{-} \mathrm{OCT} 4^{+} / \mathrm{SALL}_{4}{ }^{+} / \mathrm{SOX}_{2}{ }^{+} / \mathrm{NANOG}^{+}$ CSC subpopulations, or endothelial markers ERG or CD34 for the pSTAT3 ${ }^{+}$subpopulation on the endothelium of microvessels within the tumor. Antibodies used for PRR and ATIIR2 detection were VectaFluor Excel anti-rabbit 594 (ready-to-use; cat\# VEDK-1594, Vector Laboratories) and Alexa Fluor anti-mouse 488 (1:500; cat\#A21202, Life Technologies). Antibodies for ACE and ATIIR1 detection were VectaFluor Excel anti-mouse (ready-to-use; cat\# VEDK2488, Vector Laboratories) and Alexa Fluor antirabbit 594 (1:500; cat\# A21207, Life Technologies).

Human tissues used for positive controls were placenta for PRR, liver for ATIIR1, and kidney for ATIIR2 and ACE. Negative controls were used in secondary and tertiary antibody staining by omitting the primary antibodies on a randomly selected sample of MM to the brain.

\section{Image analysis}

DAB IHC stained-slides were viewed and images were captured with an Olympus BX53 light microscope fitted with an Olympus SC100 digital camera (Olympus, Tokyo, Japan), and processed with the CellSens 2.0 software (Olympus). IF IHC-stained images were captured using an Olympus FV1200 biological confocal laser-scanning microscope and processed with CellSens Dimension 1.11 software using 2D deconvolution algorithms (Olympus).

\section{WB}

Five snap-frozen samples of MM to the brain from the original cohort of ten patients underwent WB as described previously ${ }^{[28]}$, using the primary antibodies: anti-PRR (ATP6IP2, 1:500; cat\# ab40790, Abcam), 

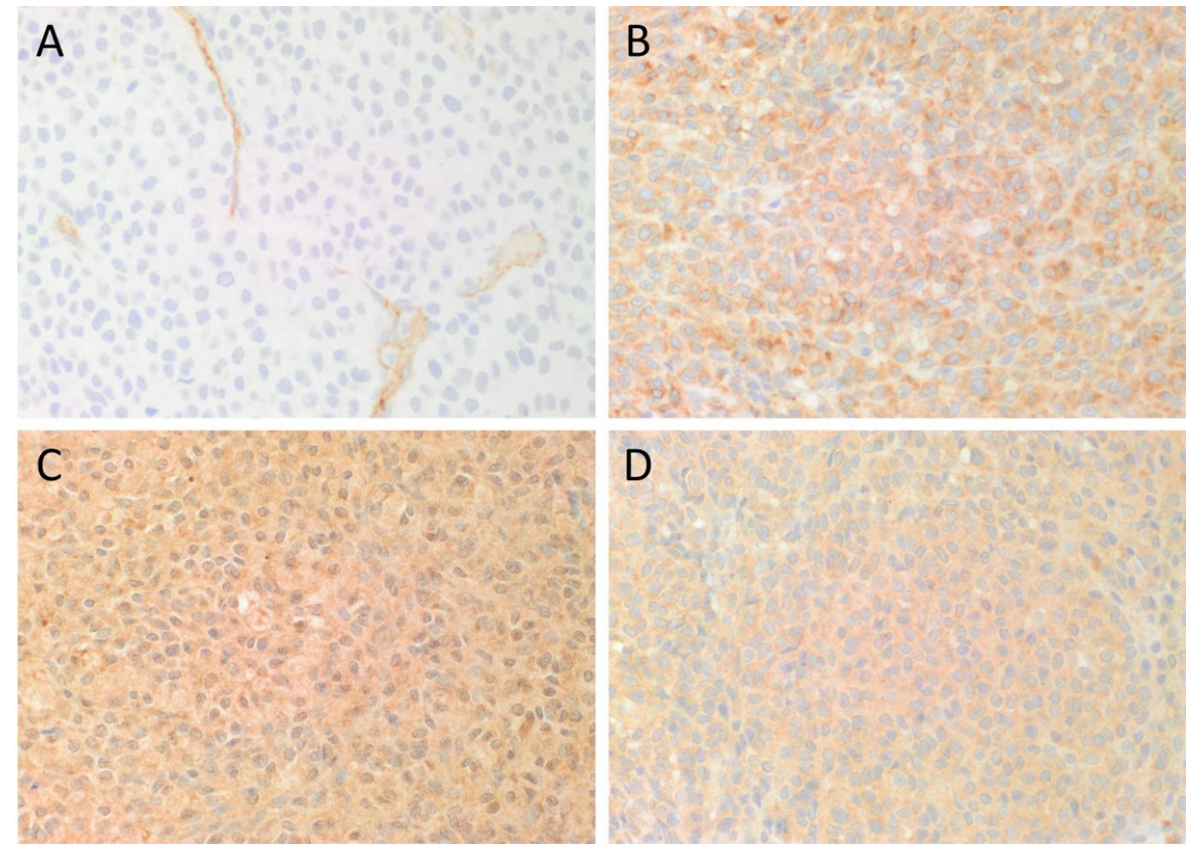

Figure 1. Representative $D A B I H C$-stained sections of metastatic melanoma to the brain showing endothelial staining of $A C E$ ( $A$, brown), and mostly cytoplasmic staining of PRR (B, brown), ATIIR1 (C, brown) and ATIIR2 (D, brown). Nuclei were counter-stained with hematoxylin (A-D, blue). Original magnification: 200x. DAB: 3, 3-diaminobenzidine; IHC: immunohistochemical; ATIIR1: angiotensin II receptor 1; ATIIR2: angiotensin II receptor 2; PRR: pro-renin receptor; ACE: angiotensin converting enzyme

anti-ATIIR1 (AT2R1, 1:500; cat\# sc-1173, Santa Cruz, CA, USA), anti-ATIIR2 (1:5000; cat\# ab92445, Abcam), anti-ACE (1:200; cat\# sc-12184, Santa Cruz) and anti- $\beta$-actin (1:2000 cat\# ab8226, Abcam). Secondary antibodies used were Alexa Fluor 647 rabbit anti-mouse for $\beta$-actin (1:2000 cat\# A21202, Thermo Fisher Scientific), donkey anti-goat HRP (1:10000; cat\# ab97120; Abcam) and a rabbit anti-goat Superclonal ${ }^{\mathrm{TM}}$ biotin conjugated secondary antibody (1:20000; cat\# A27013, Thermo Fisher Scientific) followed by a Pierce ${ }^{\mathrm{TM}}$ Streptavidin Poly-HRP (1:5000, cat\# 21140, Thermo Fisher Scientific) at $4{ }^{\circ} \mathrm{C}$ for $10 \mathrm{~min}$ for the ACE tertiary cascade. $\beta$-actin antibody probing was performed with the iBind ${ }^{\mathrm{TM}}$ Flex device (cat\# SLF2000, Life Technologies) using primary mouse monoclonal anti- $\beta$-actin (1:2000; cat\# ab8226, Abcam) and secondary donkey anti-mouse AlexaFluor 488 (1:2000; cat\# A21202, Thermo Fisher Scientific). Clarity Western ECL (cat\# 1705061, Bio-Rad) was used to visualize HRP detected bands and the Chemi Doc MP Imaging System (Bio-Rad) and Image Lab 5.0 software (Bio-Rad) were used for detection and analysis. Positive controls were mouse brain extract for PRR and ATIIR1, mouse lung protein extract for ACE and PC3 cell lysate for ATIIR2. Negative controls were mouse kidney for PRR, human tonsil for ACE, mouse kidney for ATIIR1 and NTERA2 for ATIIR2.

\section{NanoString mRNA analysis}

RNA extraction, as previously described ${ }^{[27]}$, was performed on four snap-frozen samples of MM to the brain from the same cohort of ten patients included in DAB IHC staining underwent. RNA was subjected to NanoString nCounter ${ }^{\mathrm{TM}}$ Gene Expression Assay (NanoString Technologies, Seattle, WA, USA) as completed by New Zealand Genomics Ltd (Dunedin, NZ). Probes for the genes encoding PRR (NM_005765.2), ATIIR1 (NM_000685.3), ATIIR2 (NM_000686.3), ACE (NM_000789.2) and the housekeeping gene GAPDH (NM_002046.3) were designed and synthesized by NanoString Technologies.

\section{RESULTS}

\section{Histology and DAB IHC staining}

$\mathrm{H} \& \mathrm{E}$ staining (data not shown) demonstrated the presence of MM in all ten samples that stained positively for the melanoma marker Melan-A (data not shown). The endothelium of the microvessels expressed 

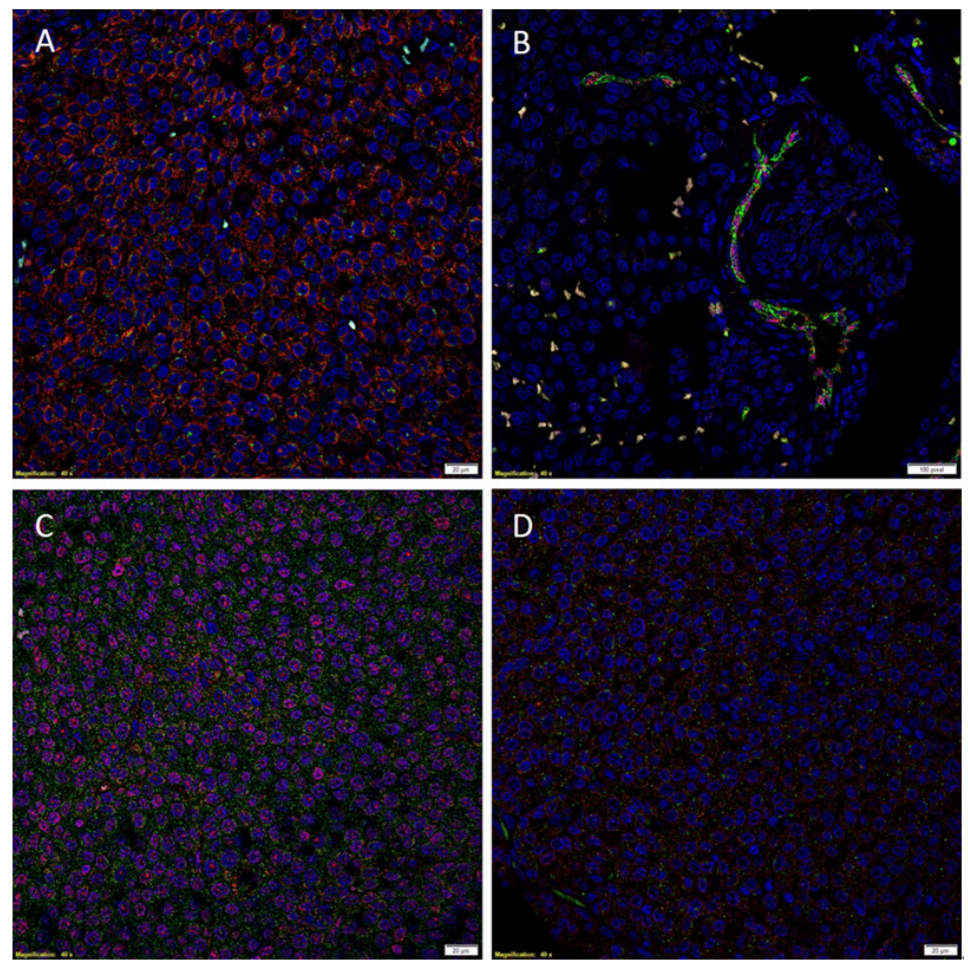

Figure 2. Representative IF IHC-stained sections of metastatic melanoma to the brain demonstrating cytoplasmic expression and some nuclear expression of PRR ( $A$, red) on the $\mathrm{OCT}_{4}^{+}\left(A\right.$, green) cells. $A C E\left(B\right.$, green) was expressed by the $\mathrm{ERG}^{+}(\mathrm{B}$, red) endothelium of the microvessls. Some NANOG ${ }^{+}\left(C\right.$, red) cells expressed ATIIR1 (C, green). ATIIR2 (D, red) was expressed in the cytoplasm of the OCT4 ${ }^{+}(D$, green) cells. Cell nuclei were counterstained with 4', 6'-diamidino-2-phenylindole (A-D, blue). Scale bars: $20 \mu \mathrm{m}$. IF: immunofluorescence; IHC: immunohistochemical; PRR: pro-renin receptor; ATIIR1: angiotensin II receptor 1; ATIIR2: angiotensin II receptor 2; ACE: angiotensin converting enzyme

ACE [Figure 1A]. The tumor tissue widely expressed PRR [Figure 1B], ATIIR1 [Figure 1C] and ATIIR2 [Figure 1D], mostly in the cytoplasm.

Human tissues used for positive controls: placenta for PRR, liver for ATIIR1, and kidney for ATIIR2 and ACE demonstrated the expected staining patterns [Supplementary Figure 1]. The omission of the primary antibody provided a control for the secondary antibody (data not shown).

\section{IF IHC staining}

IF IHC staining showed cytoplasmic expression of PRR [Figure 2A, red] on the $\mathrm{OCT}_{4}^{+}$[Figure $2 \mathrm{~A}$, green] CSCs within MM to the brain. ACE [Figure $2 \mathrm{~B}$, green] was expressed only on the $\mathrm{ERG}^{+}$[Figure $2 \mathrm{~B}$, red] endothelium of the microvessels. ATIIR1 [Figure 2C, green] was expressed by the $\mathrm{NANOG}^{+}$[Figure 2C, red] CSCs, while ATIIR2 [Figure 2D, red] was expressed on the $\mathrm{OCT}_{4}^{+}$[Figure 2D, green] CSCs in MM to the brain.

Supplementary Figure 2A-H displays individual IF IHC stains shown in Figure 2. Supplemental Figure 2I shows the appropriate negative control on a section of MM to the brain by the omission of the primary antibody.

\section{WB}

$\mathrm{PRR}$, at a molecular weight of $40 \mathrm{kDa}$, was present in all five samples of $\mathrm{MM}$ to the brain [Figure $3 \mathrm{~A}$ ]. The negative control of mouse kidney also showed a comparatively faint band. ACE, at $190 \mathrm{kDa}$, was detected in all five samples, with multiple smaller molecular weight bands detected in all the samples [Figure 3B], possibly due to degraded protein. ATIIR 1 was seen in two of the five samples at $45 \mathrm{kDa}$, with a $28-\mathrm{kDa}$ 

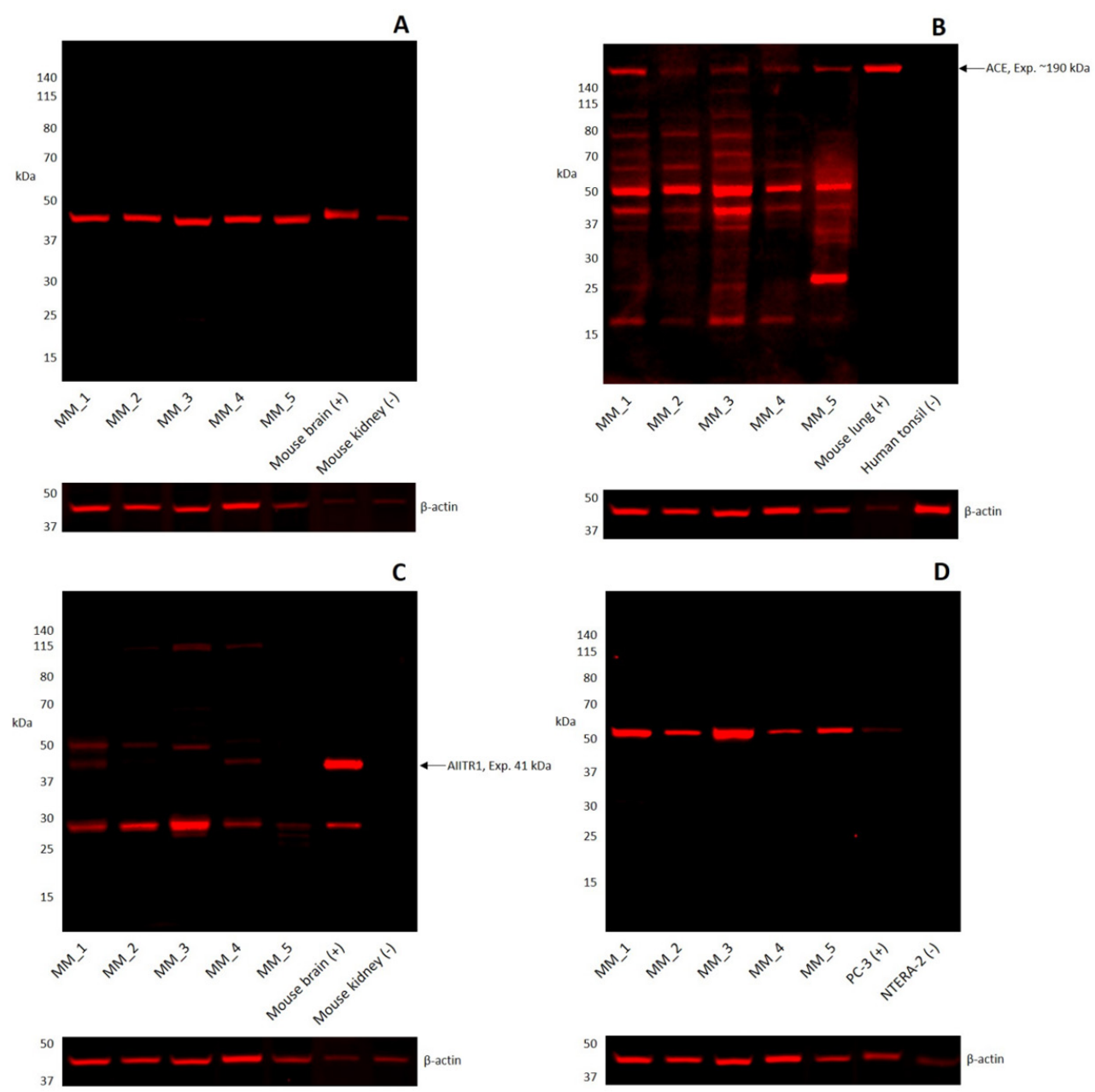

Figure 3. Representative images of Western blots performed on five samples of metastatic melanoma to the brain. PRR was detected in all five samples at $40 \mathrm{kDa}(\mathrm{A})$. ACE was detected in all five samples at $190 \mathrm{kDa}$, with multiple lower bands consistent with protein degradation (B). ATIIR1 was detected at $45 \mathrm{kDa}$ in two samples and at $28 \mathrm{kDa}$ in all five samples (C). ATIIR2 was present at $50 \mathrm{kDa}$ in all five samples $(H)$. Positive controls were mouse brain extract for PRR (A), mouse lung protein extract for ACE (B), mouse brain for ATIIR1 (C), PC3 cell lysate for ATIIR2 (D). Negative controls were mouse kidney for PRR (A), human tonsil for ACE (B), mouse kidney for ATIIR1 (C), and NTERA2 for ATIIR2 (D). PRR: pro-renin receptor; ATIIR1: angiotensin II receptor 1; ATIIR2: angiotensin II receptor 2; ACE: angiotensin converting enzyme

band was also present in all five samples and the positive control [Figure $3 \mathrm{C}$ ], possibly due to degradation. ATIIR2 was seen in all five samples at $50 \mathrm{kDa}$ [Figure 3D].

\section{NanoString mRNA analysis}

NanoString mRNA analysis revealed very high levels of mRNA expression for PRR, moderate levels of ACE and low levels of ATIIR1 mRNA expression, while ATIIR2 was below detectable levels [Figure 4].

\section{DISCUSSION}

We have recently identified three CSC subpopulations within MM to the brain: a Melan- $\mathrm{A}^{+}$subpopulation and a Melan-A subpopulations that express the ESC markers OCT4, SALL4, SOX2 and NANOG, and a $\mathrm{pSTAT}^{+}{ }^{+}$subpopulation localized to the $\mathrm{CD} 34^{+}$endothelium of the microvessels within the tumor ${ }^{[21]}$. This study demonstrated the expression of PRR, ATIIR1 and ATIIR2 by these CSCs subpopulations we have identified. The demonstration of widespread expression of these cell surface receptors by DAB IHC staining, may be due to their relatively abundant expression within the samples we have examined. Using 


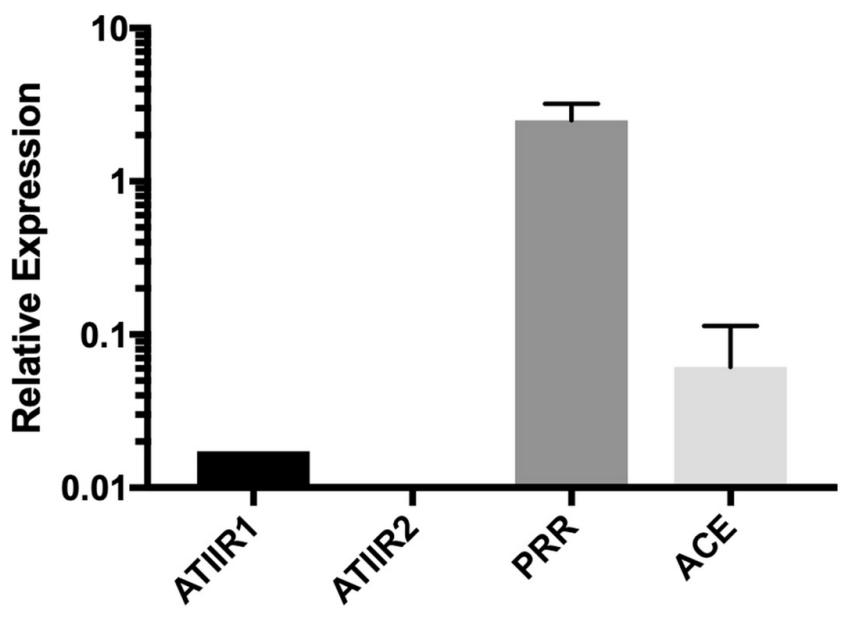

Figure 4. Relative expression of mRNA transcripts of PRR, ACE, ATIIR1 and ATIIR2 by NanoString mRNA analysis of four samples of metastatic melanoma to the brain showing high levels of expression of PRR, moderate levels for ACE, low levels for ATIIR1 and undetectable levels for ATIIR2, relative to the housekeeping gene GAPDH. PRR: pro-renin receptor; ATIIR1: angiotensin II receptor 1; ATIIR2: angiotensin II receptor 2; ACE: angiotensin converting enzyme

OCT4 and NANOG as surrogate markers, IF IHC staining revealed localization of PRR, ATIIR1 and ATIIR2 to the $\mathrm{OCT}_{4}{ }^{+} / \mathrm{OCT}_{4}{ }^{+} / \mathrm{SALL} 4^{+} / \mathrm{SOX}_{2}{ }^{+} / \mathrm{NANOG}^{+} \mathrm{CSC}$ subpopulations while ACE was localized the CSC subpopulation on $\mathrm{ERG}^{+}$endothelium of the microvessels which we have shown to express pSTAT3 previously. The expression of PRR, ACE, ATIIR1 and ATIIR2 was confirmed by WB. NanoString mRNA analysis showed high levels of expression of PRR, lower expression levels of ACE and ATIIR1. ATIIR2 was below detectable levels which may be due to mRNA degradation or its transient presence during transcription within the samples examined.

We have previously reported expression of PRR, ATIIR1 and ATIIR2 by the SOX2 ${ }^{+}$CSC subpopulation, and exclusive expression of ACE by the subpopulation on the endothelium of the microvessels, in human isocitrate dehydrogenase-wildtype $\mathrm{GB}^{[26]}$ and OCSCC affecting different subsites ${ }^{[27-29]}$. mRNA expression of renin, ACE, ATIIR1 and ATIIR2 has been demonstrated on primary cultured human keratinocytes, melanocytes, dermal fibroblasts and dermal capillary endothelial cells, but ATIIR2 is not detected in melanocytes ${ }^{[31]}$.

Cellular proliferation associated with ATI-treated and ATII-treated infantile hemangioma cell culture has shown to be diminished by ACE inhibitor ramipril and the ATIIR2 antagonist PD123319, and is enhanced by ATIIR2 agonist CGP42112 ${ }^{[32]}$, implying a role for the RAS peptides in stem cell proliferation.

Blockade of the RAS leads to inhibited growth of colorectal cancer liver metastases in the regenerating $\operatorname{liver}^{[33]}$ and recent reports of increased overall survival of GB patients treated with angiotensin receptor blockers $^{[34]}$, support the role of the RAS in cancer. It is exciting to speculate that CSCs in MM to the brain maybe a novel therapeutic target by modulating the RAS, although more work including a larger sample size, control tissue samples and in vitro and in vivo functional work is needed to determine the precise role of the RAS in this aggressive cancer.

In conclusion, in this study we have demonstrated the expression and localization of components of the components of the RAS: PRR, ACE, ATIIR1 and ATIIR2 in MM to the brain. PRR, ATIIR1 and ATIIR2 are localized to the CSC subpopulations within the tumor while ACE is expressed by the CSC subpopulation on the endothelium of the microvessels. Targeting the CSCs using modulators of the RAS may be a novel therapeutic approach for MM to the brain. 


\section{DECLARATIONS}

\section{Acknowledgements}

We thank Ms Liz Jones, Ms Alice Chibnall and Dr Jonathan Dunne of the Gillies McIndoe Research Institute for their assistance in IHC staining, tissue processing for NanoString mRNA analysis, and WB, respectively.

\section{Authors' contributions}

Formulated the study hypothesis: Itinteang T, Tan ST

Designed the study: Itinteang T, Wickremesekera AC, Tan ST

Recruited patients and obtained study samples: Wickremesekera AC, Parker A, Koeck H

Interpreted the DAB IHC data: Itinteang T, Brasch HD, Wickremesekera AC, Tan ST

Interpreted the IF IHC data: Itinteang T, Wickremesekera AC, Tan ST

Interpreted the WB and NanoString mRNA analysis data: Itinteang T, Tan ST

Drafted the manuscript: Wickremesekera AC, Itinteang T, Tan ST

All authors commented on and approved the manuscript.

\section{Availability of data and materials}

Data supporting the findings of this study can be obtained by contacting the corresponding author.

\section{Financial support and sponsorship}

None.

\section{Conflicts of interest}

All authors declared that there are no conflicts of interest. TI, PFD and STT are inventors of the provisional patents Cancer Diagnosis and Therapy (No.PCT/NZ2015/050108) and Cancer Therapeutic (PCT/NZ2018/050006), and provisional patent application Novel Pharmaceutical Compositions for Cancer Therapy (US/62/711709).

\section{Ethics approval and consent to participate}

This study was approved by the Central Health and Disabilities Ethics Committee (Ref. 15CEN28) with written informed consent from all subjects in accordance with the Declaration of Helsinki.

\section{Consent for publication}

Not applicable.

\section{Copyright}

(C) The Author(s) 2019.

\section{REFERENCES}

1. Barnholtz-Sloan S, Sloan J, Davis A, Vigneau FD, Lai F, et al. Incidence proportions of brain metastases in patients diagnosed (1973 to 2001) in the Metropolitan Detroit Cancer Surveillance System. J Clin Oncol 2004;22:2865-72.

2. Miller AJ, Mihm MC. Melanoma. N Eng1 J Med 2006;355:51-65.

3. Salvati M, Cervoni L, Caruso R, Gagliardi FM. Solitary cerebral metastasis from melanoma: value of the 'en bloc' resection. Clin Neurol Neurosurg 1996;98:12-4.

4. Hanson PW, Elaimy AL, Lamoreaux WT, Demakas JJ, Fairbanks RK, et al. A concise review of the efficacy of stereotactic radiosurgery in the management of melanoma and renal cell carcinoma brain metastases. World J Surg Oncol 2012;10:176.

5. Queirolo P, Spagnolo F, Picasso V, Spano L, Tanda E, et al. Combined vemurafenib and fotemustine in patients with BRAFV600 melanoma progressing on vemurafenib. Oncotarget 2016;9:12408-17.

6. Kienast Y, von Baumgarten L, Fuhrmann M, Klinkert WE, Goldbrunner R, et al. Real-time imaging reveals the single steps of brain metastasis formation. Nat Med 2010;16:116-22. 
7. Preusser M, Capper D, Ilhan-Mutlu A, Berghoff AS, Birner P, et al. Brain metastases: pathobiology and emerging targeted therapies. Acta Neuropathol 2012;123:205-22.

8. Hodi FS, O'Day SJ, McDermott DF, Weber RW, Sosman JA, et al. Improved survival with ipilimumab in patients with metastatic melanoma. N Engl J Med 2010;363:711-23.

9. Margolin K. The promise of molecularly targeted and immunotherapy for advanced melanoma. Curr Treat Options Oncol 2016;17:48.

10. Davies H, Bignell GR, Cox C, Stephens P, Edkins S, et al. Mutations of the BRAF gene in human cancer. Nature 2002;417:949-54.

11. Sosman JA, Kim KB, Schuchter L, Gonzalez R, Pavlick AC, et al. Survival in BRAF V600-mutant advanced melanoma treated with vemurafenib. N Engl J Med 2012;366:707-14.

12. Cagney DN, Alexander BM, Hodi FS, Buchbinder EI, Ott PA, et al. Rapid progression of intracranial melanoma metastases controlled with combined BRAF/MEK inhibition after discontinuation of therapy: a clinical challenge. J Neurooncol 2016;129:389-93.

13. Weidle UH, Birzele F, Kollmorgen G, Rüger R. Dissection of the process of brain metastasis reveals targets and mechanisms for molecular-based intervention. Cancer Genomics Proteomics 2016;13:245-58.

14. Dawood S, Austin L, Cristofanilli M. Cancer stem cells: implications for cancer therapy. Oncology (Williston Park) 2014;28:1101-7.

15. Shipitsin M, Polyak K. The cancer stem cell hypothesis: in search of definitions, markers, and relevance. Lab Invest 2008;88:459-63.

16. Al-Hajj M, Wicha MS, Benito-Hernandez A, Morrison SJ, Clarke MF. Prospective identification of tumorigenic breast cancer cells. Proc Nat Acad Sci 2003;100:3983-8.

17. Bradshaw A, Wickremesekera A, Brasch HD, Chibnall AM, Davis PF, et al. Cancer stem cells in glioblastoma multiforme. Front Surg 2016;3:48

18. Ram R, Brasch HD, Dunne JC, Davis PF, Tan ST, et al. The identification of three cancer stem cell subpopulations within moderately differentiated lip squamous cell carcinoma. Front Surg 2017;4:12.

19. Baillie R, Itinteang T, Yu HH, Brasch HD, Davis PF, et al. Cancer stem cells in moderately differentiated oral tongue squamous cell carcinoma. J Clin Pathol 2016;69:742-4.

20. Yu HH, Featherston T, Tan ST, Chibnall AM, et al. Characterization of cancer stem cells in moderately differentiated buccal mucosal squamous cell carcinoma. Front Surg 2016;3:46.

21. Wickremesekera AC, Brasch HD, Lee VM, Davis PF, Woon K, et al. Putative cancer stem cell subpopulations in metastatic melanoma to the brain. J Clin Neurosci 2019;60:112-6.

22. Deshayes F, Nahmias C. Angiotensin receptors: a new role in cancer? Trends Endocrinol Metab 2005;16:293-9.

23. Farag E, Sessler DI, Ebrahim Z, Kurz A, Morgan J, et al. The renin angiotensin system and the brain: New developments. J Clin Neurosci 2017;46:1-8.

24. Juillerat-Jeanneret L, Celerier J, Chapuis Bernasconi C, Nguyen G, Wostl W, et al. Renin and angiotensinogen expression and functions in growth and apoptosis of human glioblastoma. Br J Cancer 2004;90:1059-68.

25. Arundhathi A, Chuang WH, Chen JK, Wang SE, Shyr YM, et al. Prorenin receptor acts as a potential molecular target for pancreatic ductal adenocarcinoma diagnosis. Oncotarget 2016;7:55437-48.

26. Bradshaw AR, Wickremesekera AC, Brasch HD, Chibnall AM, Davis PF, et al. Glioblastoma multiforme cancer stem cells express components of the renin-angiotensin system. Front Surg 2016;3:51.

27. Featherston T, Yu HH, Dunne JC, Chibnall AM, Brasch HD, et al. Cancer stem cells in moderately differentiated buccal mucosal squamous cell carcinoma express components of the renin-angiotensin system. Front Surg 2016;3:52.

28. Ram RS, Brasch HD, Dunne JC, Davis PF, Tan ST, et al. Cancer stem cells in moderately differentiated lip squamous cell carcinoma express components of the renin-angiotensin system. Front Surg 2017;4:30.

29. Baillie R, Itinteang T, Yu HH, Brasch HD, Davis PF, et al. Cancer stem cells in moderately differentiated oral tongue squamous cell carcinoma express components of the renin-angiotensin system. J Clin Pathol 2016;69:942-5.

30. Tan EM, Chudakova DA, Davis PF, Brasch HD, Itinteang T, et al. Characterisation of subpopulations of myeloid cells in infantile haemangioma. J Clin Pathol 2015;68:571-4.

31. Steckelings UM, Wollschläger T, Peters J, Henz BM, Hermes B, et al. Human skin: source of and target organ for angiotensin II. Exp Dermatol 2004;13:148-54.

32. Itinteang T, Marsh R, Davis PF, Tan ST. Angiotensin II causes cellular proliferation in infantile haemangioma via angiotensin II receptor 2 activation. J Clin Pathol 2015;68:346-50.

33. Koh SL, Ager EI, Costa PLN, Malcontenti-Wilson C, Muralidharan V, et al. Blockade of the renin-angiotensin system inhibits growth of colorectal cancer liver metastases in the regenerating liver. Clin Exp Metastas 2014;31:395-405.

34. Januel E, Ursu R, Alkhafaji A, Marantidou A, Doridam J, et al. Impact of renin-angiotensin system blockade on clinical outcome in glioblastoma. Eur J Neurol 2015;22: 1304-9. 